\title{
Slope Stability Analysis Under Pore-Water Pressure: A Case Study in Zarm-Rood Earthfill Dam, Iran
}

Mojtaba Gholamzade ( $\nabla$ mojtaba.gholamzade@yahoo.com )

Islamic Azad University

Ahad Bagherzadeh Khalkhali

Islamic Azad University

\section{Research Article}

Keywords: Landslide, Slope stability, Zarm-Rood, SLOPE/W, Pore-water Pressure

Posted Date: June 1st, 2021

DOI: https://doi.org/10.21203/rs.3.rs-498150/v1

License: (c) (i) This work is licensed under a Creative Commons Attribution 4.0 International License.

Read Full License 


\title{
Slope Stability Analysis Under pore-water Pressure: A case study in Zarm- Rood Earthfill Dam, Iran
}

\begin{abstract}
It is well known that construction of dams or reservoirs have geomorphological impacts on the environment and could potentially accelerate the occurrence of landslides. One of the most common impact is the occurrence of new landslides and activation of the old one, which may turn into a natural disaster. Thus, controlling the stability of landslides become challenging issue specifically in the presence of f pore-water pressure. In general, the presence of water or porewater pressure reduces the soil resistance and also leads to increase in stimulus loads, resulting in reduction of stability coefficients. In the present study, using GeoStudio SLOPE/W software, the effect of the proximity of the dam reservoir in terms of different operating conditions on the stability analysis of the landslide area of Zarm-Rood Dam is investigated. In the first step, the evaluation of internal stability of landslides and the effect of the presence of water on stability coefficients were evaluated and then the sustainable design of landslides was proposed. It was found that when extra pore-water pressure ranges from 0.2 to 0.4 , safety factor is decreased by about $10 \%$. Accordingly, safety factor is decreased by about $17 \%$ when extra pore-water pressure range from 0.4 to 0.6 . This research demonstrates successful implementation of GeoStudio SLOPE/W for slope stability analysis in dam construction projects.
\end{abstract}

Keywords: Landslide, Slope stability, Zarm-Rood, SLOPE/W, Pore-water Pressure

\section{1-Introduction}

Landslides are one of the main challenging issue in the field of geotechnical engineering and one of the most dominate geological hazards with considerable financial damage worldwide. Main 
driving factors for mass movements or landslides can be divided into two categories known as external and internal factors (Zhou et al., 2018). Tectonic movements, earthquakes and tremors are considered as internal causes while rain and snow, structural changes, rapid drawdown, seepage from springs, the impact of vegetation are classified as external causes. One of the most challenging issues in stability of landslides is the presence of water pressure. In general, the presence of pore-water pressure reduces the soil resistance and also increases the stimulus loads, thus reducing the stability coefficients against stability (Wang and Sassa, 2003). Excessive water pressure is occurred in the proximity of dam reservoirs to landslides, in some operational conditions such as rapid drawdown of the reservoir. In the present study, the effect of dam reservoir in different operational conditions on landslide stability is investigated. The internal stability of landslide is evaluated based on stress analysis and then, the effect of the presence of water on the stability coefficients are evaluated.

\section{2-Research background}

In recent years, many studies have been conducted in the field of landslide analysis and associated factors. Tang et al. (2017) modified limit equilibrium method to find the coefficient of slope stability for different water pressure, shear strength, rock layers and also identified a potential slip page. Bowa (2020) presented the mechanism of effective factors in the occurrence of landslides in Chenaran watershed in North Khorasan province and provided potential landslide zonation map based on the effective factors with LIM model. Casagli et al. (2006) conducted a study to map the landslide susceptibility using logistic regression analysis and GIS in north of Iran. They have found that the slope, proximity to roads, elevation, aspect and soil units was found to be the most effective factors in landslides respectively. Duncan and Dunlop (1969) carried out research to produce landslide susceptibility map of the Balason River basin, Darjeeling Himalaya, using a logistic 
regression model using GIS and Remote Sensing. They employed serval factors including topographic and hydrologic parameters, geology, soil, land use/land cover and serval proximity parameters. They found that all the independent variables were statistically significant. In another study Feng et al. (2018) presented a methodology for landslide susceptibility analysis in Jeju Island, South Korea using Analytic Hierarchy Process and Artificial Neural Network methods. Gao (2014) employed Naive Bayes Classifier to predict slope stability for a slope subjected to circular failures, based on six input factors including slope height, slope angle, cohesion, friction angle, unit weight, and pore-water pressure ratio. In terms of both accuracy and applicability they confirmed that Naive Bayes Classifier model provide better result when compared to the existing empirical approach. In another study Guo et al. (2019) employed ABAQUS software package to investigated the effect seepage on slope stability using the modified Duncan-Chang model as well as considering the interaction between seepage field and soil stress. Janbu (1957) conducted a research on numerical analysis of seepage and slope stability in an Earthen dam by using Slope/w Software. The simulation results revealed that upstream and downstream side of the dam section has a direct effect on the factor of safety.

Few other researchers have conducted research on the water level drawdown and its effects on slope stability. Amoung those $\mathrm{Xu}$ and Yang (2018) suggested that the critical pore-water pressure distribution can be assigned to about 0.43 or $\mathrm{u}=0.43 \gamma \mathrm{H}$. Based on their analysis, the pore-water pressure can be $30 \%$ higher in $3 \mathrm{D}$ analysis if compared with the $2 \mathrm{D}$ analysis. In a recent studies Luo et al. (2018) conducted a research on wedge sliding analysis of the rock slope subjected to uplift forces and surcharge loads conditions. They identified that the safety factor of the slope susceptible to wedge sliding decreases with an increase in the surcharge loads and the uplift forces acting along the joint planes due to water pressure. 
Raghuvanshi (2019) has conducted a comprehensive review of analysis techniques such as conventional kinematic methods including equilibrium, probabilistic and numerical methods including continuous and hybrid methods for rock slope failure modes. Mondal and Mandal (2018) compared the LEM equilibrium methods and the two finite element methods including the SRM power reduction method and the ELSM limit resistance method to determine the slope safety factor and find the slip potential plate. Morgenstern and Price (1965) investigated the effect of geofabric reinforcements on earthen slopes. For this purpose, they used static and quasi-static stability analyzes and compared different methods of slope stability analysis. Tang et al. (2017) investigated the effect of changes in the parameters of piles used to stabilize gables using 3D finite element method using the Flac 3D program.

$\mathrm{Ng}$ and Pang (2000) proposed a centrifugal model for slope analysis under rapid drainage conditions and investigated deformations and fracture behaviors in geotextile-resistant slopes. Least but not the last, Krabbendam and Hall (2019) performed a numerical analyses of transient seepage in unsaturated soil slopes using the measured stress-dependent soil-water characteristic curves and predicted that the distributions of pore-water pressure can be significantly different from those predicted by the analyses using the soil-water characteristic curves. Dispute of many other researches related to slope stability and its effective parameters in different conditions, research on slope stability under pore-water pressure induced by water level drawdown or rising water level in dam reservoir are still rare. This research designed to investigate the possibility of slope sliding in both side of the Zarm-Rood Dam reservoir in operational condition using SLOPE/W software.

\section{2-1-Governing Equations of Stability Analysis}


Slope module is used to perform stability analyzes using GeoStudio software. So far, various methods have been proposed to calculate the reliability coefficient of slope stability such as Pyke (1991), Quan and Lee (2012), Raghuvanshi (2019), Sarma (1979), USACE (2003) Spencer (1967) and Wang and Sassa (2003). In this research, the Morgenstern-Price method has been used to analyze the stability in static and quasi-static conditions due to more straightforwardness of this method and its popularity among others researches (Casagli et al., 2006, Gao, 2014, Guo et al., 2019). Moreover, the slip surface can be considered as circular or polygonal. To calculate the reliability coefficient in case of granular soil, the slippery mass must be divided into an optional number of slices, then internal forces and inter-part forces are obtained for each slice. The more slices the higher degree of accuracy is achieved. Fig. 1 shows a diagram of the forces acting on a slice of circular slip surface.

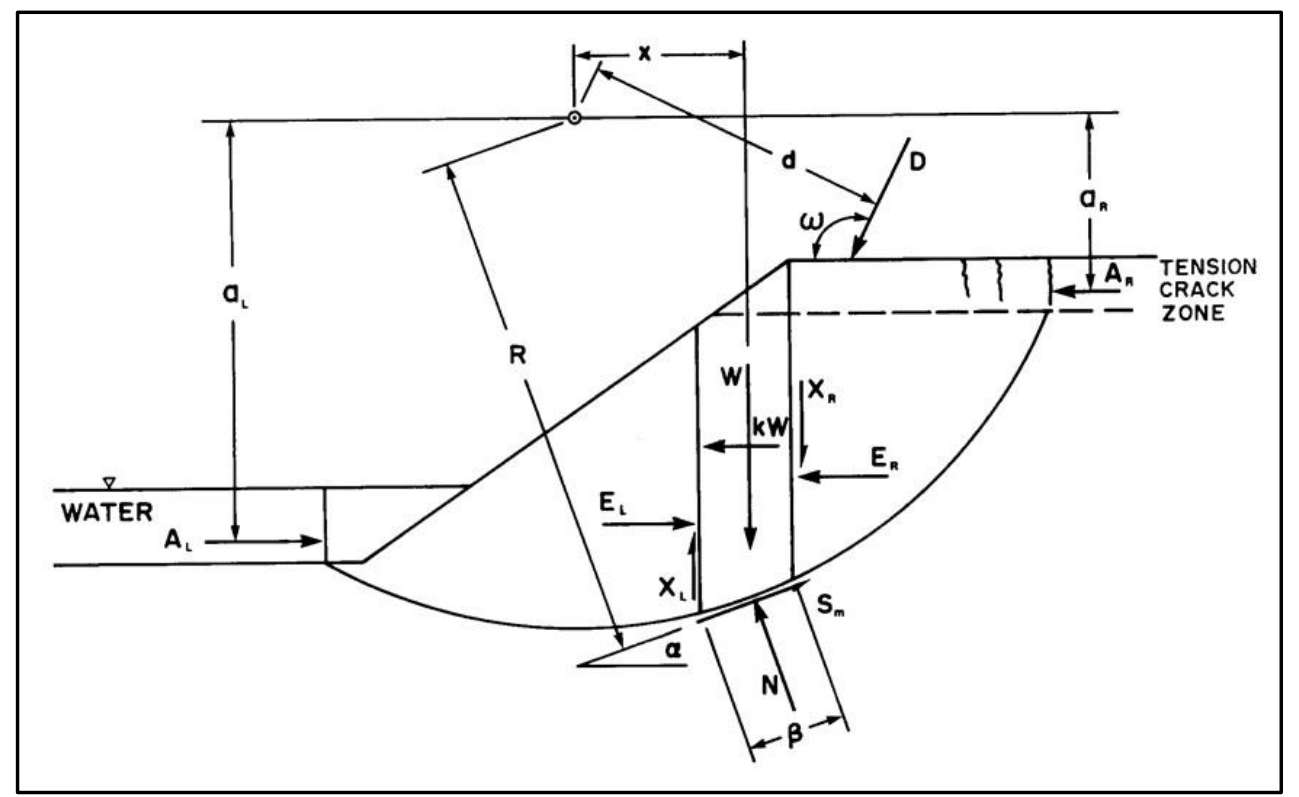

Fig. 1. Slice discretization and slice forces in a sliding mass with a circular slip surface Calculation of reliability against stability in Morgenstern-Price method: 
In the Morgenstern-Price method, two reliability coefficient is defined (Xu and Yang, 2018). One is based on moment equilibrium $\left(F_{m}\right)$ and the other is based on the result of the forces equilibrium in the horizontal direction $\left(F_{f}\right)$.

Moment equilibrium factor of safety:

$F_{m}=\frac{\sum\left(c^{\prime} \beta R+(N-u \beta) R \tan \phi^{\prime}\right)}{\sum W_{x}-\sum N f+\sum k W \pm \sum D d \pm \sum A a}$

Where;

$c^{\prime}=$ Effective cohesion of soil,$\phi^{\prime}=$ Effective internal friction angle of soil, $\beta=$ slice base length,

$W=$ the total weight of a slice, $N=$ the total normal force on the base of the slice $(W$ cos $\alpha)$,

$a=$ the perpendicular distance from the resultant external water force to the center of rotation or to the center of moments. The L and $R$ subscripts designate the left and right sides of the slope,

$A=$ the resultant external water forces. $k W=$ the horizontal seismic load applied through the centroid of each slice, $u=$ pore-water pressure, $D=$ external point load

Force equilibrium factor of safety:

$F_{f}=\frac{\sum\left(c^{\prime} \beta \cos \alpha+(N-u \beta) \tan \phi^{\prime} \cos \alpha\right)}{\sum N \sin \alpha+\sum k W-\sum D \cos \omega \pm \sum A}$

Where,

$\omega=$ the angle of the point load from the horizontal. This angle is measured counter-clockwise from the positive $x$-axis. $\alpha=$ slice base inclination 
Which in the above relations $\mathrm{N}$ is slice normal force at the base and obtained from Eq. (3) If we ignore the interslice shear forces:

$N=\frac{W-\left[\frac{c^{\prime} \beta \sin \alpha+u \beta \tan \phi^{\prime} \sin \alpha}{F_{S}}\right]+[D \sin \omega]}{\cos \alpha+\frac{\sin \alpha \tan \phi^{\prime}}{F_{S}}}$

In this method, the interslice shear force is presented as the following empirical equation proposed by (Raghuvanshi (2019)):

$X=E \lambda f(x)$

where, $f(x)$ is a function, $\lambda$ is the percentage (in decimal form) of the function used, $E$ is the interslice normal force and $X$ is the interslice shear force

Where $\lambda$ is the percentage (in decimal form) of the function used, and

$f(x)$ is interslice force function representing the relative direction of the resultant interslice force and in this study the half-sine function is considered.

The relationship between the normal forces between a piece on the left and right of each piece of slip mass is:

$E_{R}=E_{L}+\frac{\left(c^{\prime} \beta-u \beta \tan \phi^{\prime}\right) \cos \alpha}{F_{S}}+N\left(\frac{\tan \phi^{\prime} \cos \alpha}{F_{s}}-\sin \alpha\right)-k W+D \cos \omega$

By repeating these steps and changing the scale factor $\lambda$, the ratio of shear force to normal force between the slices are changed so that both reliability coefficients tend to be a constant value. In this way, both the moment and force equilibrium equations in the horizontal direction will be satisfied.

\section{2-2-Selection of Quasi-Static Coefficient}


SLOPE /W software, like all limit equilibrium methods, considers the effects of earthquake forces on slope stability quasi-statically by applying the horizontal acceleration coefficient of the earthquake and the vertical acceleration coefficient of the earthquake as a fraction of gravitational acceleration if necessary. This should be considered that the inertial forces caused by the earthquake are usually applied to the structure in a fraction of a minute, while in the quasi-static method these forces are replaced by a permanent forces. According to the reputable sources, including the US Army Corps of Engineers (USACE, 2003) and Zhou et al. (2018), the horizontal acceleration of earthquake for the dam in case of permanent seepage loading is 0.163 gravitational acceleration (ie $0.163 \mathrm{~g}$ ) and for loading at the end of construction is equal to 0.1 gravitational acceleration (ie $0.1 \mathrm{~g}$ ). These values are equal to 0.1 gravitational acceleration (ie $0.1 \mathrm{~g}$ ) and 0.08 for the overburden in the case of permanent seepage loading and rapid water loss, respectively. In landslide stability analyzes, an earthquake coefficient of 0.163 has been used for permanent stability conditions. It is believed that the choice of horizontal acceleration coefficient for quasistatic analysis of the surface for permanent conditions is 0.163 conservatively. It should be mention that the vertical acceleration factor at the same time increase or reduce the amount of driving forces and resistant, therefore it is not required to apply vertical acceleration factor. (Krabbendam and Hall, 2019). In these studies, the vertical acceleration factor has been omitted.

\section{3-Material and method}

\section{3-1-Study Area}

The Zarm-Rood dam is located in Zarm-Rood with approximately $25 \mathrm{~km}$ Southeast of Sari, Iran (see Fig. 2). The geographical coordinates of the dam axis are $53^{\circ} 17^{\prime} 37^{\prime \prime} \mathrm{E}$ and $36^{\circ} 26^{\prime} 30^{\prime \prime} \mathrm{N}$. 


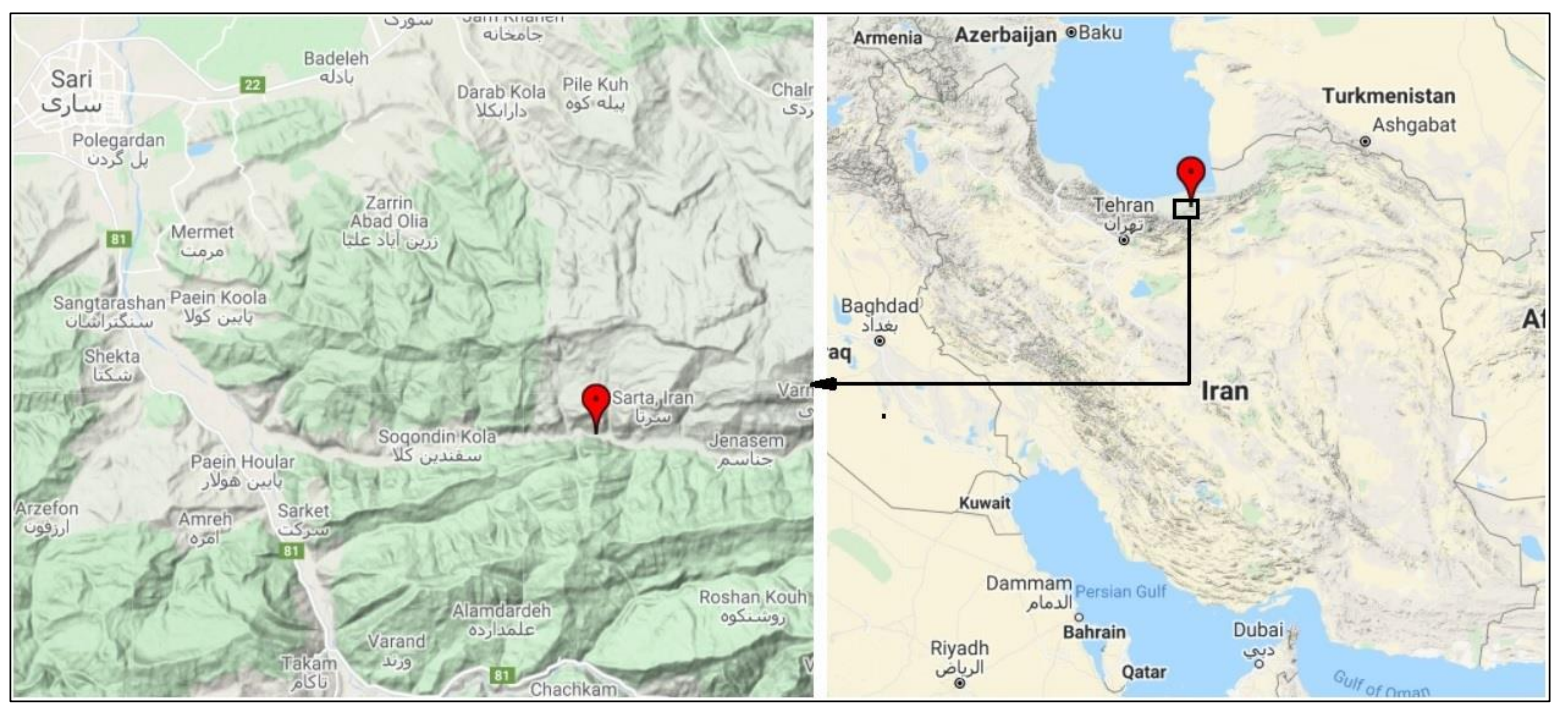

Fig. 2: Location of study area

The main faults of the region are known as Caspian fault with about $600 \mathrm{~km}$ long from the Caspian zone in the North to Alborz deposits in the South. Existing faults in North of Alborz are inverted with a steep slope to the south and it seems that the southern block along the North Alborz fault is inclined inversely on the central part and thus raises the Triassic and Jurassic deposits and in It is located next to the younger Cretaceous and Miocene deposits. There is main fault called North Alborz in which crossing from about $23 \mathrm{~km}$ South of the Dam site. Another major fault called Takam fault with Northeast-Southwest orientation and length of $49 \mathrm{~km}$, crossing from the $6.2 \mathrm{~km}$ South of the site. It is a left-slip fault and connects to the North Alborz fault.

\section{3-2-Geotechnical Parameters of Landslides}

Due to the project requirement, additional geotechnical studies have been carried out in 2018 . The result of this analysis ware approved by the professional committee members from the Ministry of Energy who were actually responsible for the approval of the technical reports of Zarm-Rood. In parallel with the detailed rock experiments, soil analysis has also been carried out and approved 
by the committee members. An example of these results are presented in Table 1. The complete set of soil and rock experiments can be obtained from the Farakhak Pishro Consulting Company.

Table 1: Sample summary of the results of resistance tests on soil materials

\begin{tabular}{|c|c|c|c|c|c|c|c|c|c|c|}
\hline \multirow{3}{*}{$\mathrm{DH}-\mathrm{NO}$} & \multirow{3}{*}{$\mathrm{DEPTH}(\mathrm{m})$} & \multicolumn{2}{|c|}{ UUT* test } & \multicolumn{4}{|c|}{ CUT** test } & $\gamma$ & $\omega_{N}$ & $\gamma_{d}$ \\
\hline & & C & $\varnothing$ & $C$ & $\varnothing$ & $C^{\prime}$ & $\emptyset^{\prime}$ & \multirow{2}{*}{$\mathrm{kN} / \mathrm{m}^{2}$} & \multirow{2}{*}{$(\%)$} & \multirow{2}{*}{$\mathrm{kN} / m^{2}$} \\
\hline & & $\mathrm{kN} / \mathrm{m}^{2}$ & Deg & $\mathrm{kN} / \mathrm{m}^{2}$ & Deg & $\mathrm{kN} / \mathrm{m}^{2}$ & Deg & & & \\
\hline $\mathrm{BH}-2$ & $0.00-0.70$ & 69 & 5 & 60 & 7 & 56 & 8 & 19.9 & 19.6 & 16.7 \\
\hline $\mathrm{BH}-2$ & $0.70-2.00$ & 63 & 4 & 59 & 6 & 53 & 9 & 21.5 & 21.5 & 16.5 \\
\hline $\mathrm{BH}-5$ & $6.15-6.50$ & 46 & 9 & 43 & 12 & 39 & 16 & 21.2 & 21.2 & 16.1 \\
\hline $\mathrm{BH}-5$ & $12.00-12.40$ & 59 & 6 & 55 & 8 & 50 & 11 & 26.3 & 26.3 & 15.5 \\
\hline $\mathrm{BH}-5$ & $19.75-20.00$ & 54 & 8 & 47 & 11 & 43 & 14 & 19.2 & 19.2 & 16.9 \\
\hline $\mathrm{BH}-5$ & $23.00-23.50$ & 56 & 7 & 50 & 10 & 47 & 12 & 23.0 & 23.0 & 16.1 \\
\hline $\mathrm{BH}-5$ & $27.00-27.50$ & 67 & 5 & 58 & 6 & 55 & 7 & 19.1 & 19.1 & 17.2 \\
\hline $\mathrm{BH}-5$ & $29.60-30.00$ & 69 & 5 & 63 & 8 & 60 & 10 & 19.7 & 19.7 & 17.3 \\
\hline $\mathrm{BH}-6$ & $18.80-22.60$ & 56 & 10 & - & - & - & - & 20.3 & 20.8 & 16.8 \\
\hline
\end{tabular}

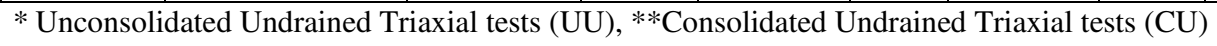

According to the analyzed data from the investigated landslides in the study area (table 1), geotechnical specifications of landslides for three different conditions including undrained, undrained-consolidated and drained conditions can be grouped as shown in table 2. 
Table 2. Different mode parameters

\begin{tabular}{lcc}
\multicolumn{1}{c}{ Mode } & $\mathrm{C}\left(\mathbf{k N} / \mathbf{m}^{\mathbf{2}}\right)$ & $\varnothing$ (Deg) \\
\hline Undrained & $60-69$ & $4-5$ \\
Undrained- consolidated & $55-59$ & $5-6$ \\
Drained & $50-55$ & $6-9$
\end{tabular}

As can be seen, due to the fine-grained type of materials, which are mainly clay with low liquid limit, practically due to the lack of pre-solidification of materials; No significant differences in resistance is observed in different laboratory tests. The specific gravity of the saturated materials was found to be 2.0 and $16.6 \mathrm{kN} / \mathrm{m}^{3}$ in dry conditions.

\section{3-3-Analysis Modes}

According to the design phase of the project and turning to the objectives of the study, the following scenarios have been identified for evaluation of slope stability related to investigated landslides:

- Long-term stability (permanent) - Full reservoir operation at normal level

- Rapid drawdown mode of the reservoir from normal level

- Long-term stability mode with the force caused by the earthquake.

Slope stability analysis were performed in comply with recommended safety factors by US Army Corps of Engineers (USACE, 2003) as listed in Table 3. 
Table 3: Minimum required factors of safety for new earth and rock-fill dams

\begin{tabular}{lcc} 
Analysis condition & Factors of safety & Slope \\
\hline End-of- Construction( including staged & 1.3 & Up and downstream \\
construction & 1.5 & Downstream \\
Long-term (steady seepage, maximum storage & & \\
pool, spillway crest or top of gates & 1.4 & Downstream \\
Maximum surcharge pool & $1.1-1.3$ & Upstream
\end{tabular}

\section{3-4-Identified Landslides at the vicinity of the Dam}

According to the previous research on seismology of the study area, it is believing that landslides are generally occurred as a result of major earthquake on 1935 with magnitude of 6.3 . The characteristics of landslides were reported in the engineering geology report at feasibility stage and the location of landslides in the vicinity of dam are shown in Fig. 3. 


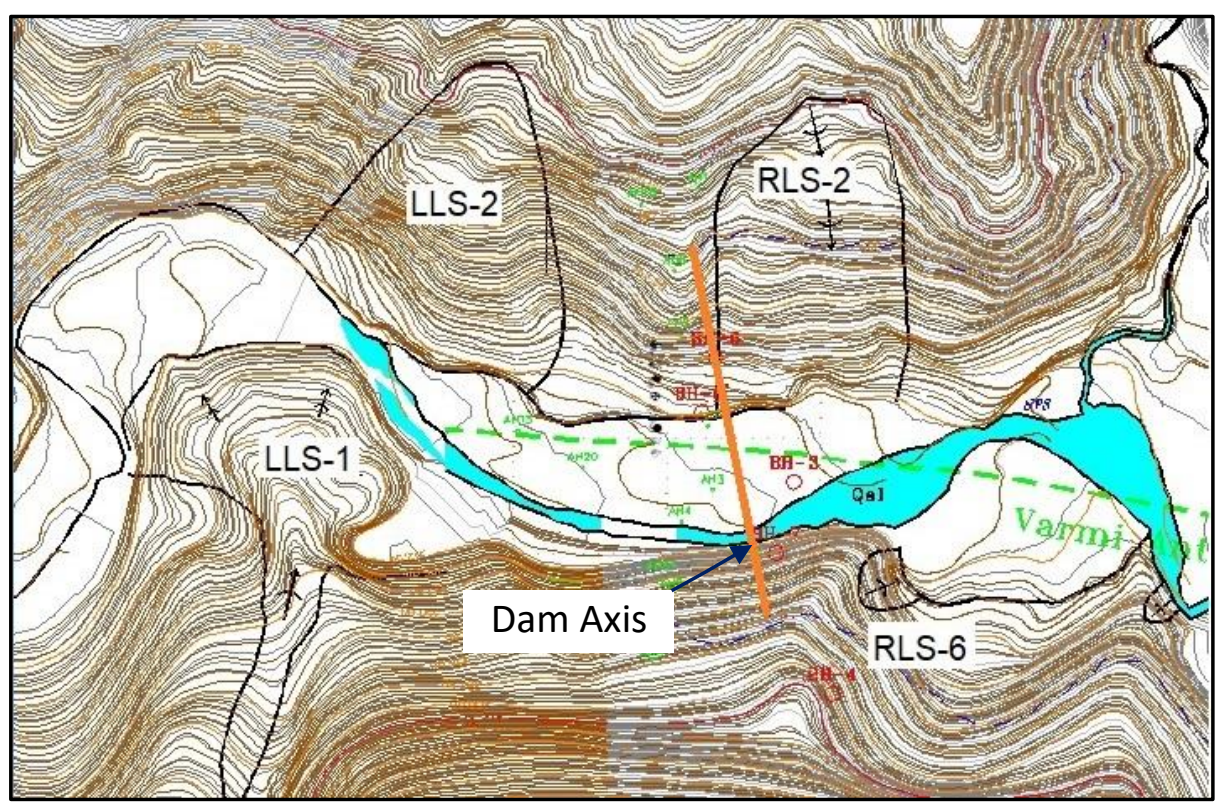

Fig. 3: Landslide location map at the vicinity of construction site

\section{4-Results and discussion}

With reference to the geotechnical studies, the main landslides for stability analysis are landslides RLS2 and RLS6 which are located in the vicinity of the reservoir and partially will be submerged under water after dewatering of Zarm-Rood Dam. Therefore, accurate and detailed information about mechanical properties of these landslides play crucial role for proper analysis. To select these parameters correctly, the geotechnical parameters of the materials used in the analysis of the Zarm-Rood Dam (dam site) was used. We have also used the lab report of the soil samples taken from the excavations as well as the effect of reverse analysis on the selected mechanical parameters of soil samples taken from the landslides. The results of landslide reversal analysis for RLS2, RLS6 in static condition are shown in Fig. 4. 


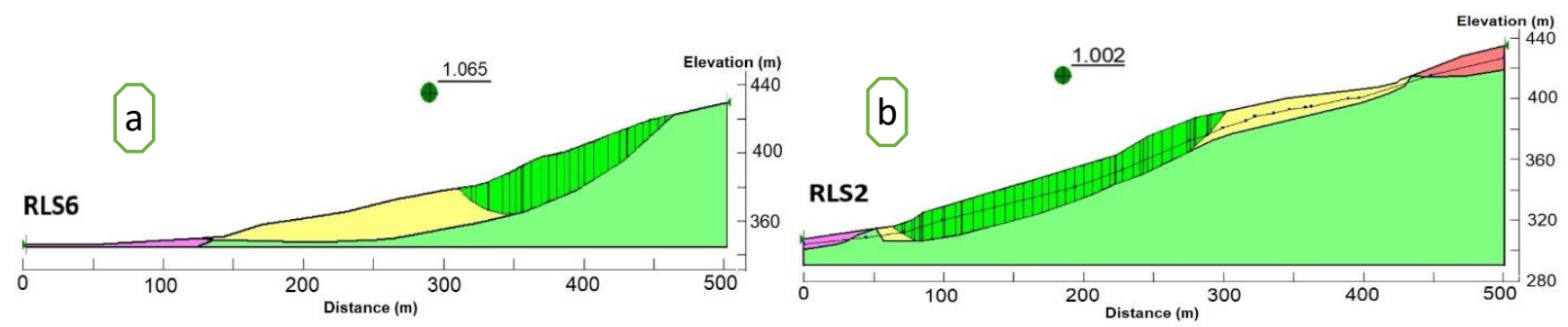

Fig. 4: Reversal analysis (static conditions) a) Landslide RLS6, b) Landslide RLS2

Based on the aforementioned analysis on RLS2 and RLS6, the cohesion and internal fraction angle was found to be $69 \mathrm{kN} / \mathrm{m}^{2}$ and $4^{\circ}$ respectively. Thus, low safety factor of 0.485 and 0.692 for RLS2 and RLS6 indicate that slope instability could be occurred under seismic conditions as illustrated in Fig. 5.

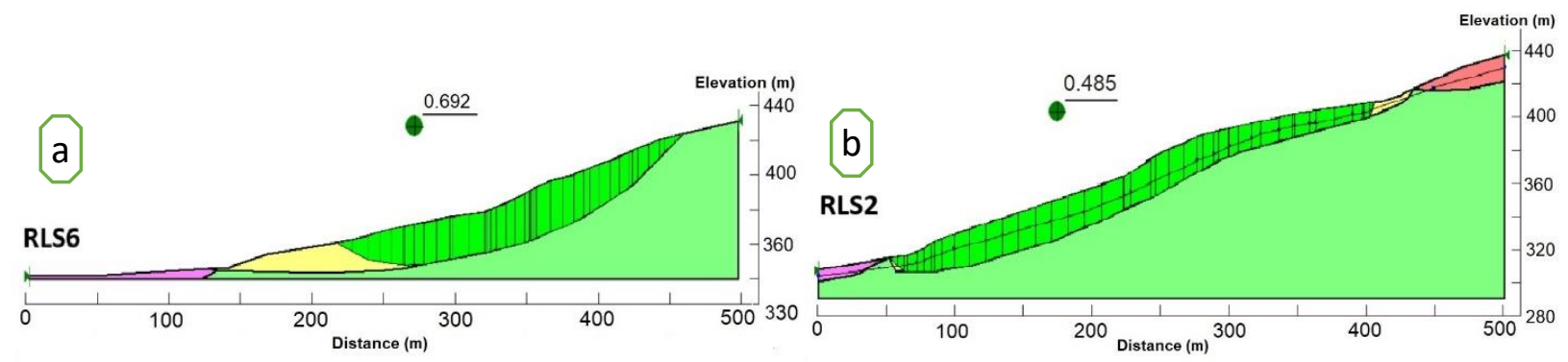

Fig. 5: Landslide analysis under quasi-static conditions a) Landslide RLS6, b) Landslide RLS2

Since these landslides are located near the Zarm-Rood Dam reservoir; Therefore, it should be stable under the loading and operational phase specifically in the conditions of rapid drawdown of the reservoir. The slope reliability coefficients of this landslide with the geometric conditions in full reservoir level and its rapid discharge performed and illustrated in Figs. 6 and 7, respectively. Examination set of results related to the stability of these landslides in different situations shows 
long-term instability with the current geometry specifically in rapid draw down condition. Hence, it is necessary to consider appropriate measures for permanent stability and safety.
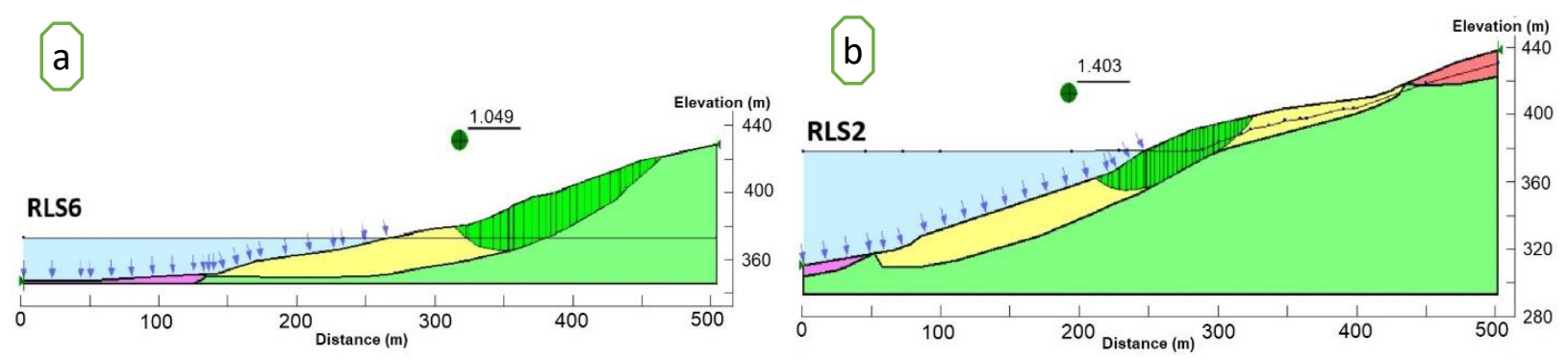

Fig. 6: Landslide analysis under static conditions of full reservoir level, a) Landslide RLS6, b)

\section{Landslide RLS2}

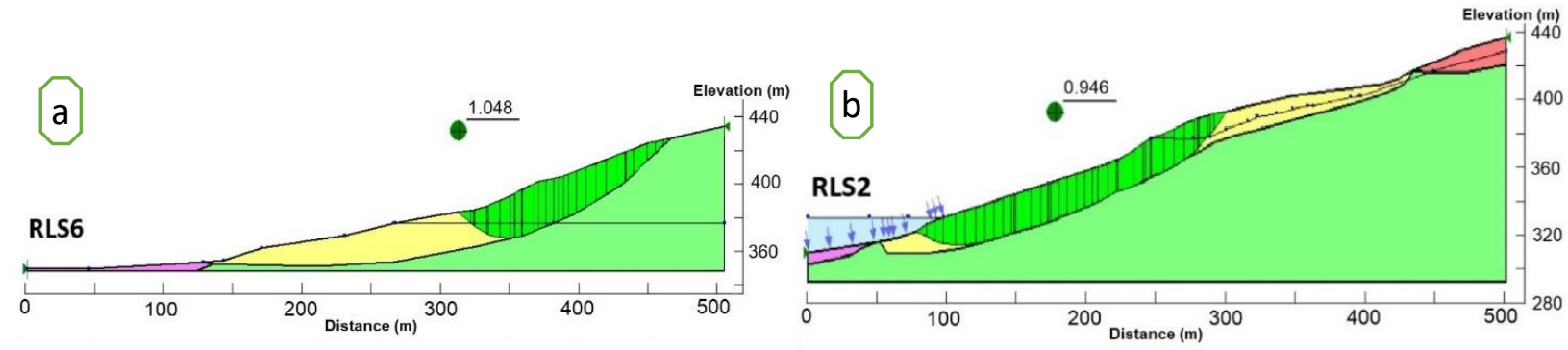

Fig. 7: Landslide analysis under static conditions of rapid draw down, a) Landslide RLS6, b)

\section{Landslide RLS6}

Various stabilization designs have been proposed for these type of slopes. To ensure permanent stability, excavation of soil from the proposed area on the top of landslide more recommended. By this approach a stable design in static and quasi-static conditions are obtained and illustrated in Figs. 8 and 9.

Stable design is performed for the RLS6 landslide critical section by soil excavation and lightening at the area $1365 \mathrm{~m}^{2}$ with specified extension which require lightening of mass volume about $540000 \mathrm{~m}^{3}$. Applying the same approach for RLS2 lead to excavate the area of $2048 \mathrm{~m}^{2}$ with 
specified extension which require lightening of mass volume about 783,000 $\mathrm{m}^{3}$. As shown in Fig. 9, safety factor reaches up to 2.213 and 1.929 for RLS6 and RLS2 respectively after lighting under static conditions.

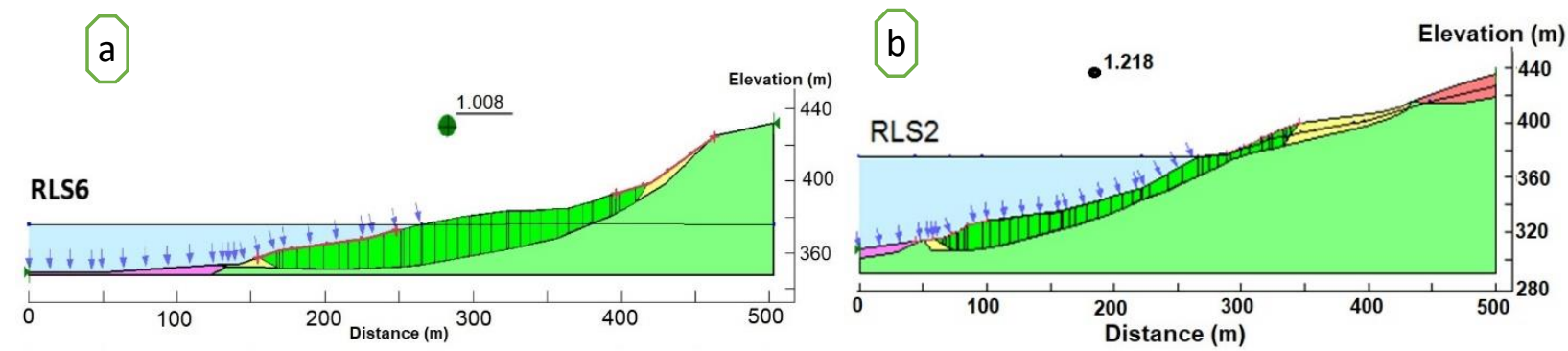

Fig 8: Stable landslide analysis under quasi-static full tank condition, a) Landslide RLS6, b) Landslide RLS2

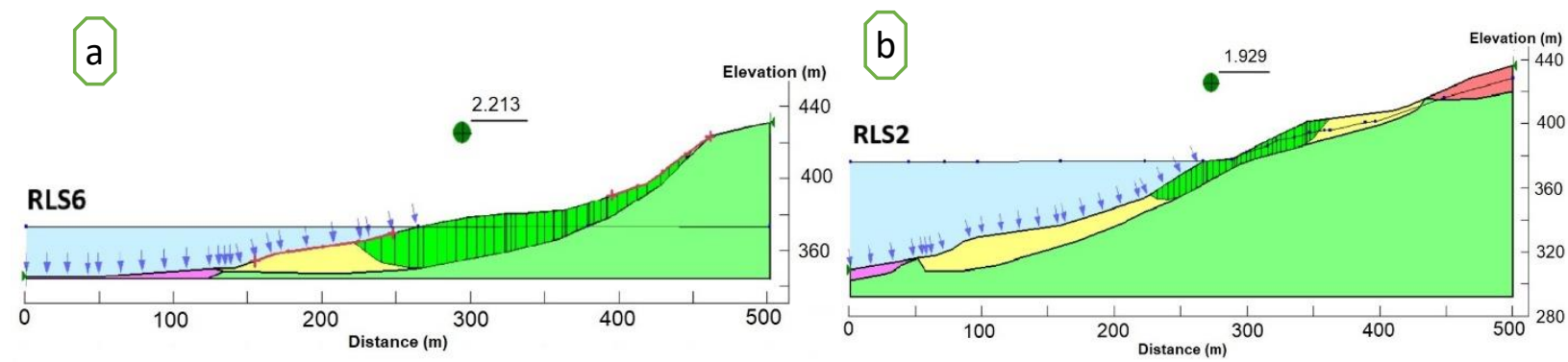

Fig. 9: Stable design analysis under static conditions - full tank, a) Landslide RLS6, b) landslides RLS2

From the investigated cases under the empty and full reservoir level, it was found that the extra pore-water pressure between of 0.2 to 0.4 lead to decrease the safety factor about 10 percent. Also, the extra pore-water pressure from 0.4 to 0.6 decrease the safety factor of stability up to 17 percent. 


\section{5-Conclusion and remarks}

Slope stability analysis is a preventive measure before or after construction project become under operation specifically in dam construction which slope failure may cause irreparable damages to the society and the environment. This study conducted to investigate slope analysis in proposed Dam in Zarm-Rood located in north of Iran. Among several occurred landslides, two of them including RLS2 and RLS6 were identified more complex. Based on the available evidence more landslides have been occurred on the bedrock surface. The main reasons are associated with the deposition of soil materials in steep and unstable position and steep slope of the bed-rocks in both sides of the valleys. In general, the best solution to ensure the long-term stability of susceptible areas for sliding in Zarm-Rood Dam site is to reduce the motive forces. This is important due to the low strength of the materials and sharp inclination of bedrocks. Likewise, in order to reduce the weight of the susceptible areas to landslide, excavation of soil from the proposed area on the top of landslide is recommended. To meet the minimum required safety factors for the slope stability various lightening plans were proposed. Reference to the stable design determined in the critical section from RLS6, it is mandatory to excavate $1365 \mathrm{~m}^{2}$ in specified depth to reach the required safety factor. This lightening step would require to relocate $540000 \mathrm{~m}^{3}$ soil materials. The same safety measures were applied to the RLS2 and it was found that $2048 \mathrm{~m}^{2}$ should be excavated and lightened, which require to relocate $783000 \mathrm{~m}^{3}$ soil materials from the top of landslide. It was also found that when pore-water pressure ranges from 0.2 to 0.4 , safety factor is decreased by about $10 \%$. Accordingly, safety factor is decreased by about $17 \%$ when extra pore-water pressure range from 0.4 to 0.6 . This research demonstrates successful implementation of GeoStudio SLOPE/W for slope stability analysis in dam construction projects and could be extended by incorporating more available options for stability analysis and slide functions. 
Acknowledgment: We cordially appreciate Farakhak Pishro Consulting Company for providing all necessary resources and lab reports for this research. The same goes to the filed experts from the company who assist and provide technical help.

\section{References}

BOWA, V. M. 2020. Wedge Sliding Analysis of the Rock Slope Subjected to Uplift Forces and Surcharge Loads Conditions. Geotechnical and Geological Engineering, 38, 367-374. DOI:10.1007/s10706019-01027-4

CASAGLI, N., DAPPORTO, S., IBSEN, M., TOFANI, V. \& VANNOCCI, P. 2006. Analysis of the landslide triggering mechanism during the storm of 20th-21st November 2000, in Northern Tuscany. Landslides, 3, 13-21, DOI: 10.1007/s10346-005-0007-y

DUNCAN, J. M. \& DUNLOP, P. 1969. Slopes in stiff fissured clays and shales. Journal of the Soil Mechanics and Foundations Division (ASCE), 94, 28.

FENG, X., LI, S., YUAN, C., ZENG, P. \& SUN, Y. 2018. Prediction of slope stability using naive Bayes classifier. KSCE Journal of Civil Engineering, 22, 941-950, DOI: 10.1007/s12205-018-1337-3

GAO, W. 2014. Forecasting of landslide disasters based on bionics algorithm (Part 1: Critical slip surface searching). Computers and Geotechnics, 61, 370-377, DOI: 10.1016/j.compgeo.2014.06.007

GUO, M., LIU, S., YIN, S. \& WANG, S. 2019. Stability analysis of the Zhangmu multi-layer landslide using the vector sum method in Tibet, China. Bulletin of Engineering Geology and the Environment, 78, 4187-4200,DOI: 10.1007/s10064-018-1386-3

JANBU, N. Earth pressures and bearing capacity calculations. Proc., 4th ICSMFE, 1957. 207-212.

KRABBENDAM, M. \& HALL, A. M. 2019. Subglacial Block Removal: A Preliminary Analysis of Driving and Resisting Forces Under Different Glaciological Scenarios, Svensk Kärnbränslehantering $\mathrm{AB} /$ Swedish Nuclear Fuel and Waste Management Company.

LUO, F., ZHANG, G., LIU, Y. \& MA, C. 2018. Centrifuge modeling of the geotextile reinforced slope subject to drawdown. Geotextiles and Geomembranes, 46, 11-21, DOI: 10.1016/j.geotexmem.2017.09.001

MONDAL, S. \& MANDAL, S. 2018. RS \& GIS-based landslide susceptibility mapping of the Balason River basin, Darjeeling Himalaya, using logistic regression (LR) model. Georisk: Assessment and Management of Risk for Engineered Systems and Geohazards, 12, 29-44, DOI: 10.1080/17499518.2017.1347949

MORGENSTERN, N. U. \& PRICE, V. E. 1965. The analysis of the stability of general slip surfaces. Geotechnique, 15, 79-93, DOI: 10.1680/geot.1965.15.1.79

NG, C. W. \& PANG, Y. 2000. Influence of stress state on soil-water characteristics and slope stability. Journal of geotechnical and geoenvironmental engineering, 126, 157-166, DOI: 10.1061/(ASCE)1090-0241(2000)126:2(157)

PYKE, R. 1991. Selection of seismic coefficients for use in pseudo-static slope stability analyses. Consulting Engineer, Lafayette.

QUAN, H.-C. \& LEE, B.-G. 2012. GIS-based landslide susceptibility mapping using analytic hierarchy process and artificial neural network in Jeju (Korea). KSCE Journal of Civil Engineering, 16, 1258-1266, DOI: 10.1007/s12205-012-1242-0

RAGHUVANSHI, T. K. 2019. Plane failure in rock slopes-A review on stability analysis techniques. Journal of King Saud University-Science, 31, 101-109, DOI: 10.1016/j.jksus.2017.06.004 
SARMA, S. K. 1979. Stability analysis of embankments and slopes. Journal of Geotechnical and Geoenvironmental Engineering, 105.

SPENCER, E. 1967. A method of analysis of the stability of embankments assuming parallel inter-slice forces. Geotechnique, 17, 11-26, DOI: 10.1680/geot.1967.17.1.11

TANG, H., YONG, R. \& ELDIN, M. E. 2017. Stability analysis of stratified rock slopes with spatially variable strength parameters: the case of Qianjiangping landslide. Bulletin of engineering geology and the environment, 76, 839-853, DOI: 10.1007/s10064-016-0876-4

USACE 2003. Engineering and design: slope stability, engineering manual EM 1110-2-1902. Department of the Army, Corps of Engineers, Office of the Chief of Engineers.

WANG, G. \& SASSA, K. 2003. Pore-pressure generation and movement of rainfall-induced landslides: effects of grain size and fine-particle content. Engineering geology, 69, 109-125, DOI: 10.1016/S0013-7952(02)00268-5

XU, J.-S. \& YANG, X.-L. 2018. Three-dimensional stability analysis of slope in unsaturated soils considering strength nonlinearity under water drawdown. Engineering Geology, 237, 102-115, DOI: 10.1016/j.enggeo.2018.02.010

ZHOU, C., YIN, K., CAO, Y., INTRIERI, E., AHMED, B. \& CATANI, F. 2018. Displacement prediction of steplike landslide by applying a novel kernel extreme learning machine method. Landslides, 15, 22112225, DOI: 10.1007/s10706-019-01027-4 
Figures

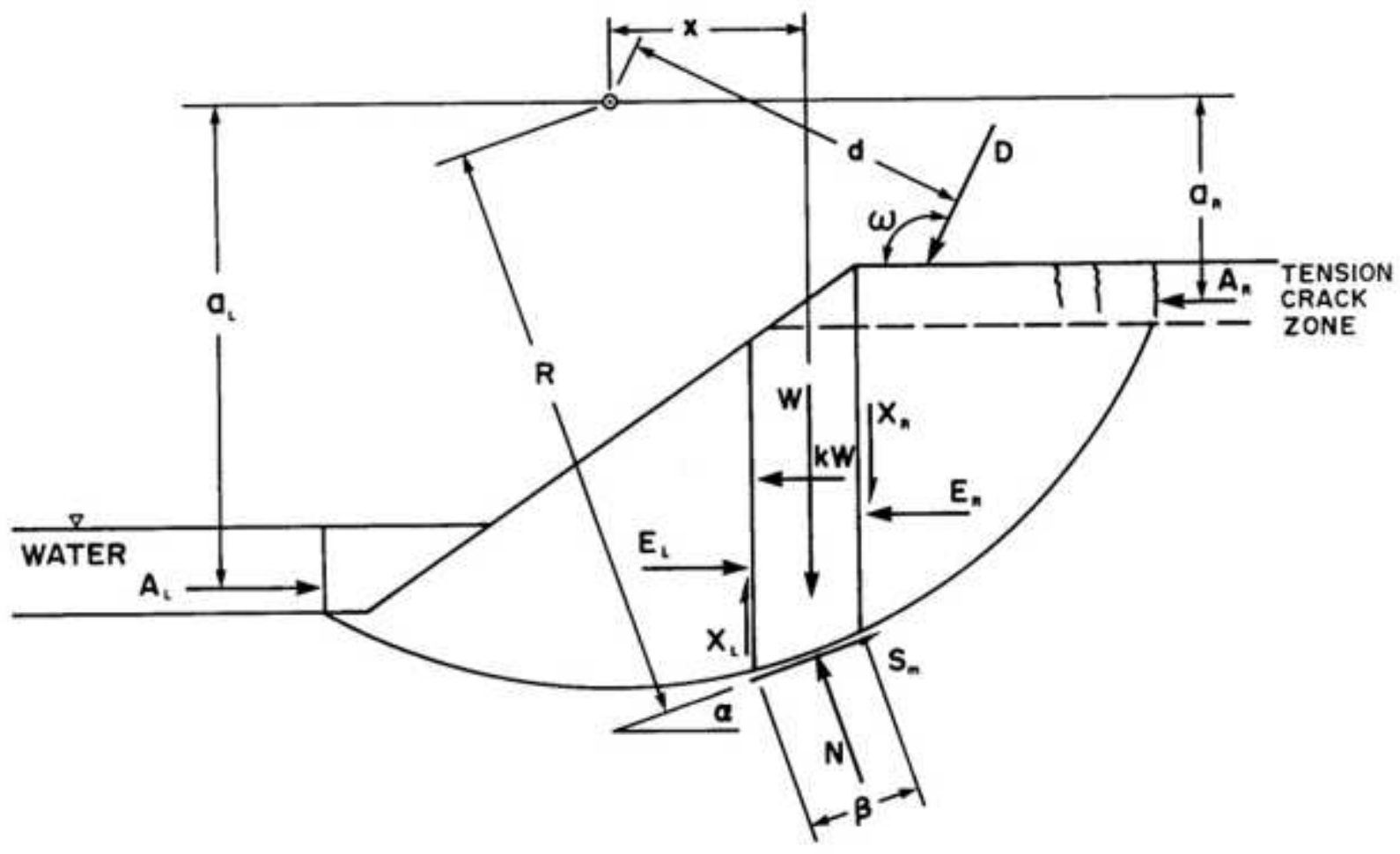

Figure 1

Slice discretization and slice forces in a sliding mass with a circular slip surface

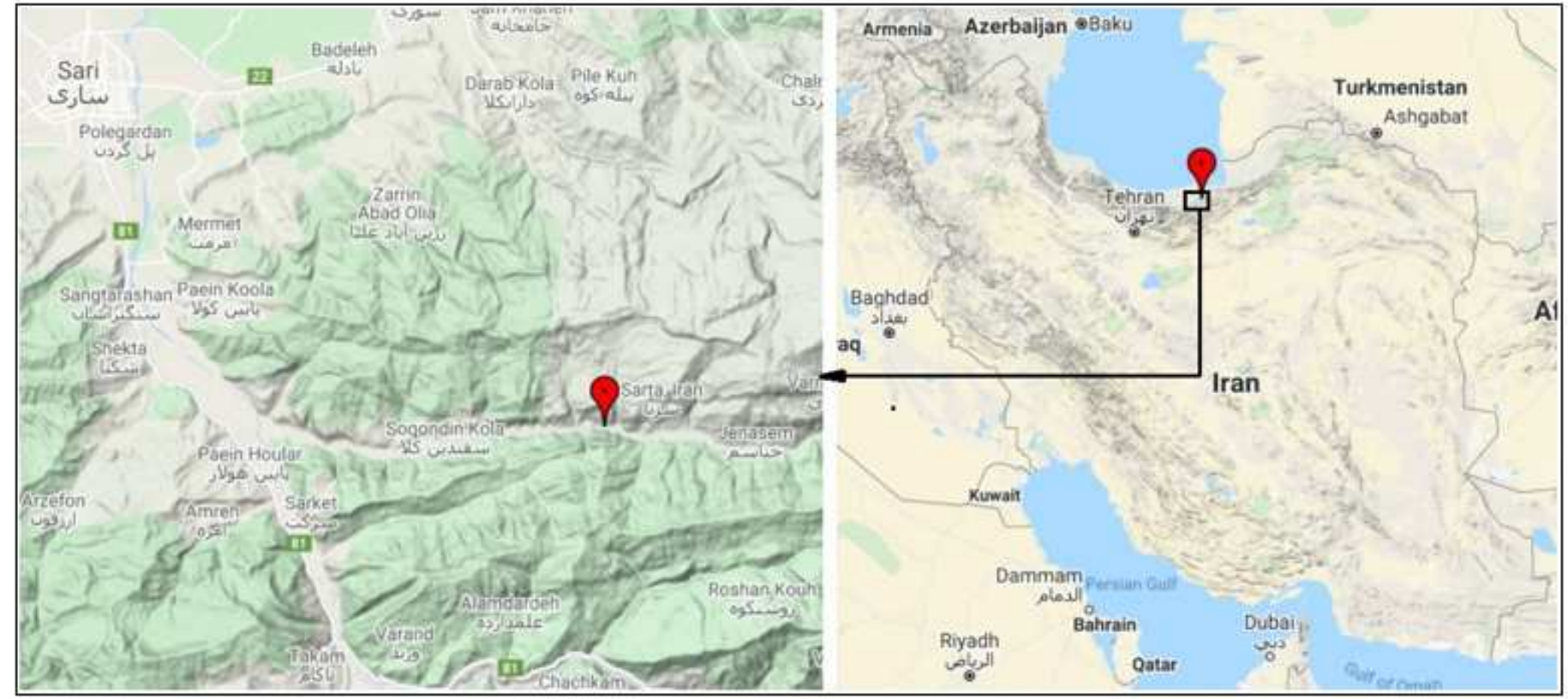

Figure 2 
Location of study area. Note: The designations employed and the presentation of the material on this map do not imply the expression of any opinion whatsoever on the part of Research Square concerning the legal status of any country, territory, city or area or of its authorities, or concerning the delimitation of its frontiers or boundaries. This map has been provided by the authors.

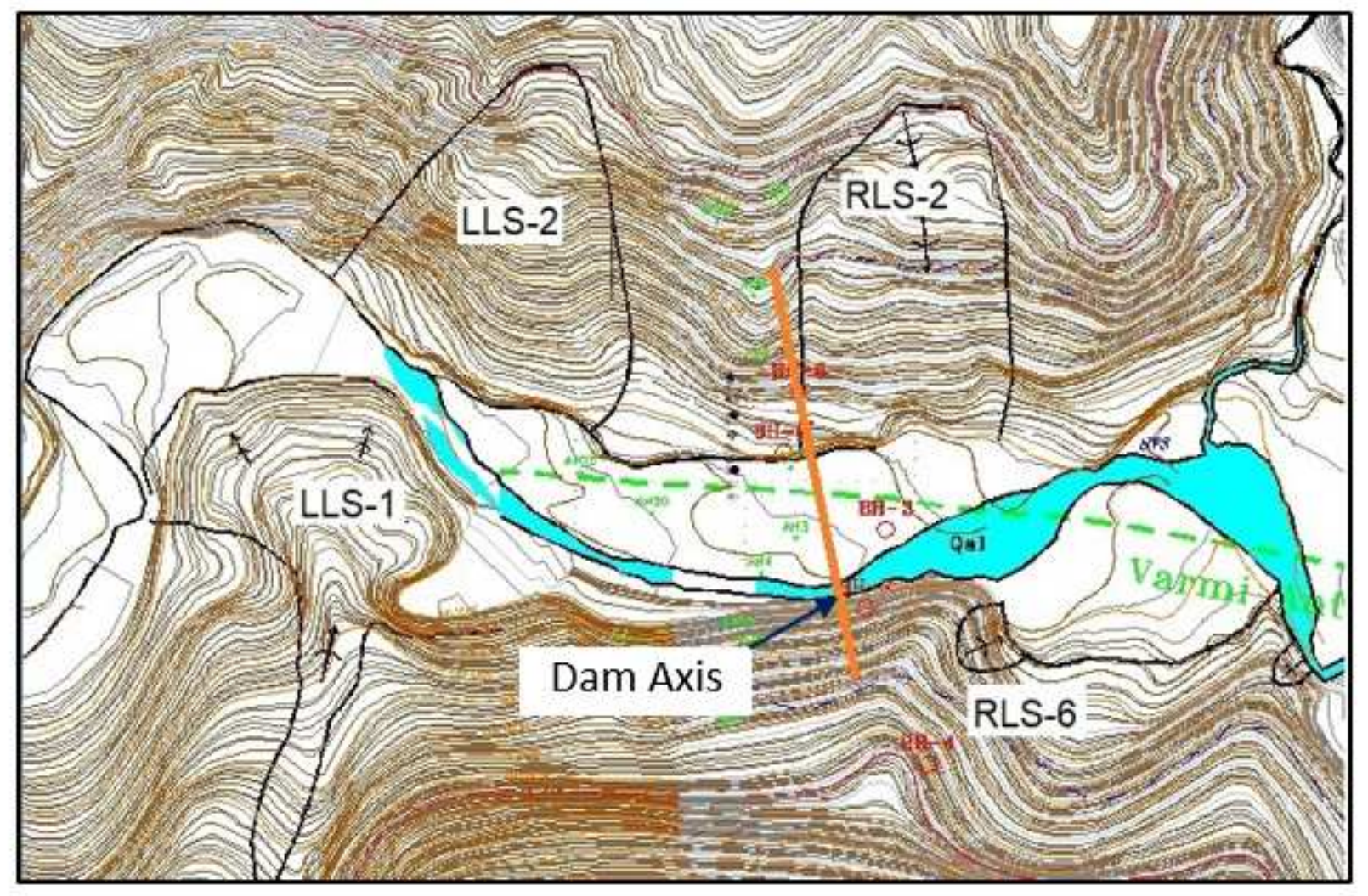

\section{Figure 3}

Landslide location map at the vicinity of construction site. Note: The designations employed and the presentation of the material on this map do not imply the expression of any opinion whatsoever on the part of Research Square concerning the legal status of any country, territory, city or area or of its authorities, or concerning the delimitation of its frontiers or boundaries. This map has been provided by the authors.

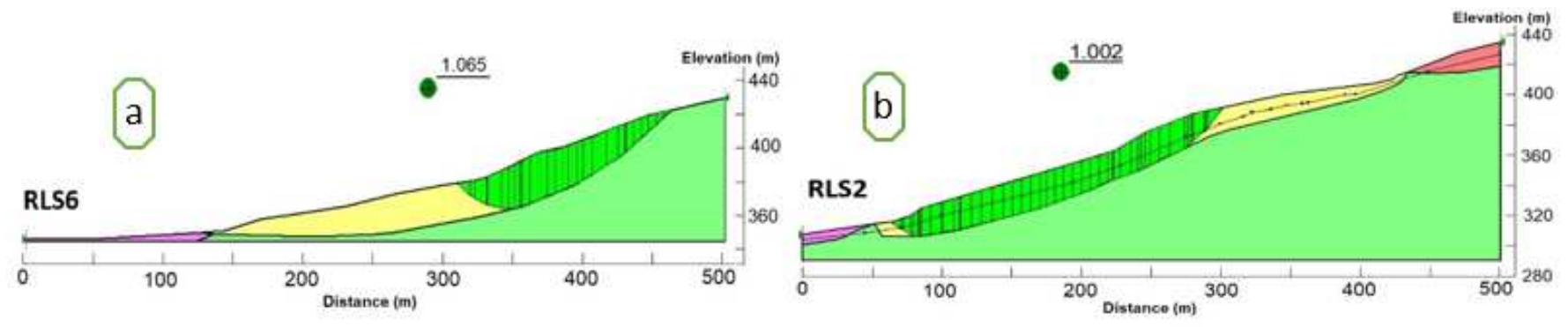

Figure 4 
Reversal analysis (static conditions) a) Landslide RLS6, b) Landslide RLS2

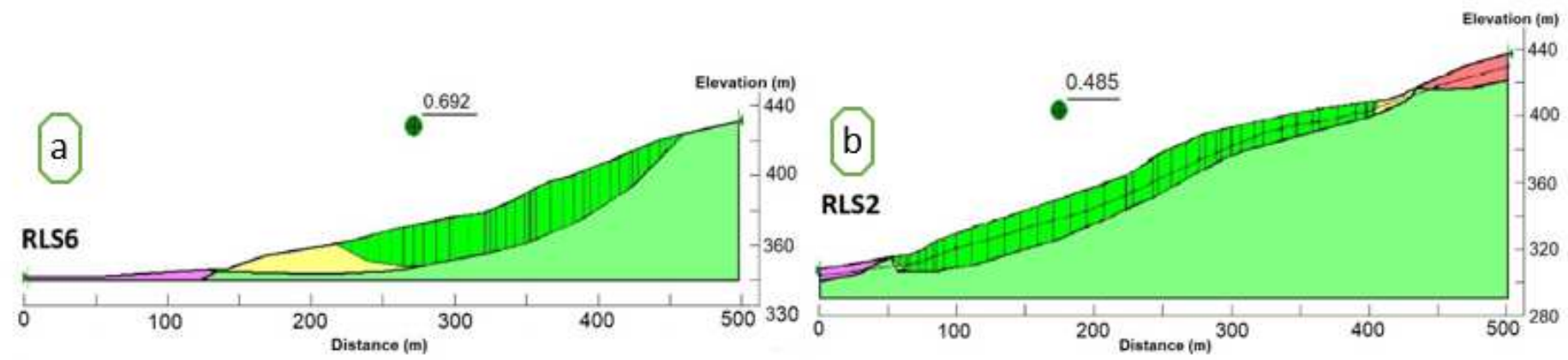

\section{Figure 5}

Landslide analysis under quasi-static conditions a) Landslide RLS6, b) Landslide RLS2
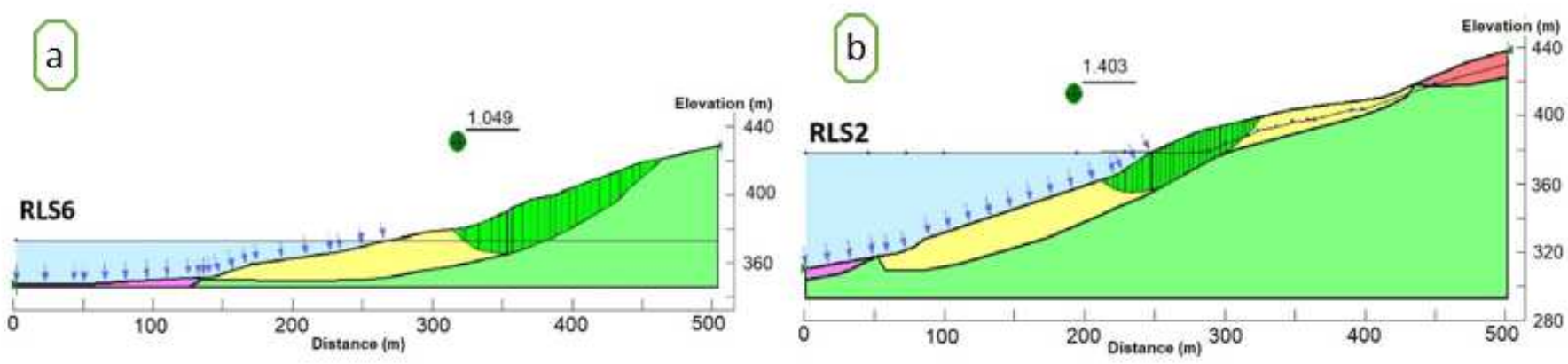

\section{Figure 6}

Landslide analysis under static conditions of full reservoir level, a) Landslide RLS6, b) Landslide RLS2
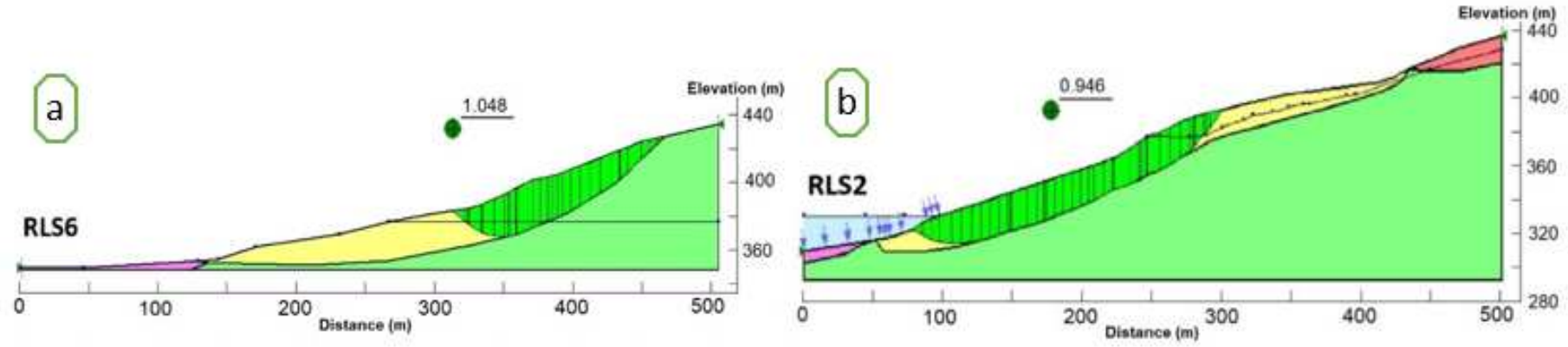

\section{Figure 7}

Landslide analysis under static conditions of rapid draw down, a) Landslide RLS6, b) Landslide RLS6 
(a)

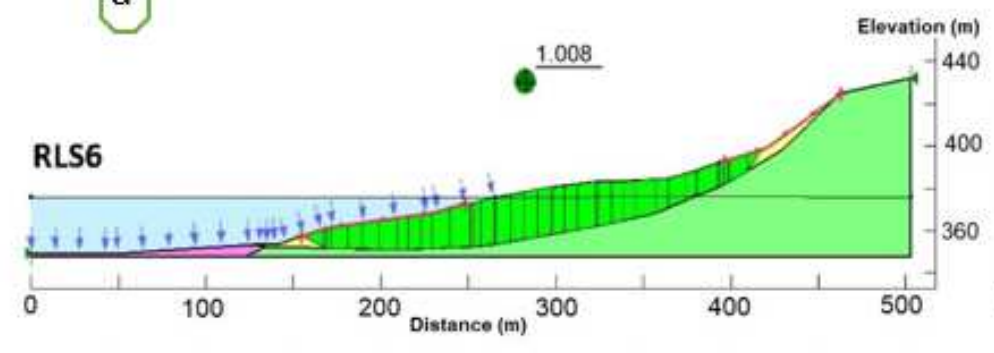

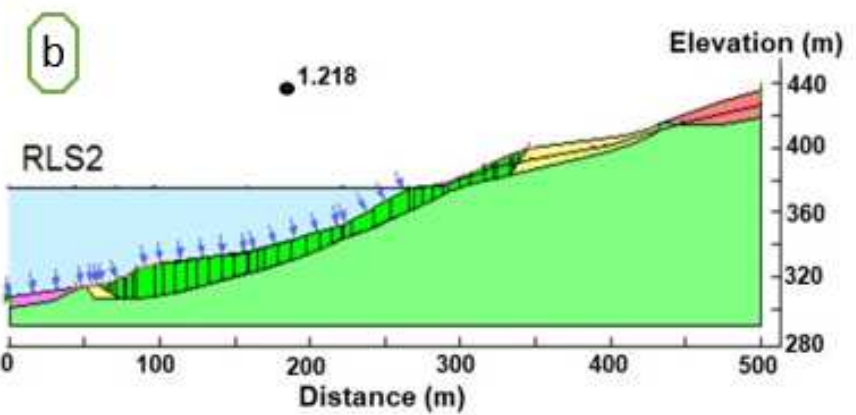

Figure 8

Stable landslide analysis under quasi-static full tank condition, a) Landslide RLS6, b) Landslide RLS2

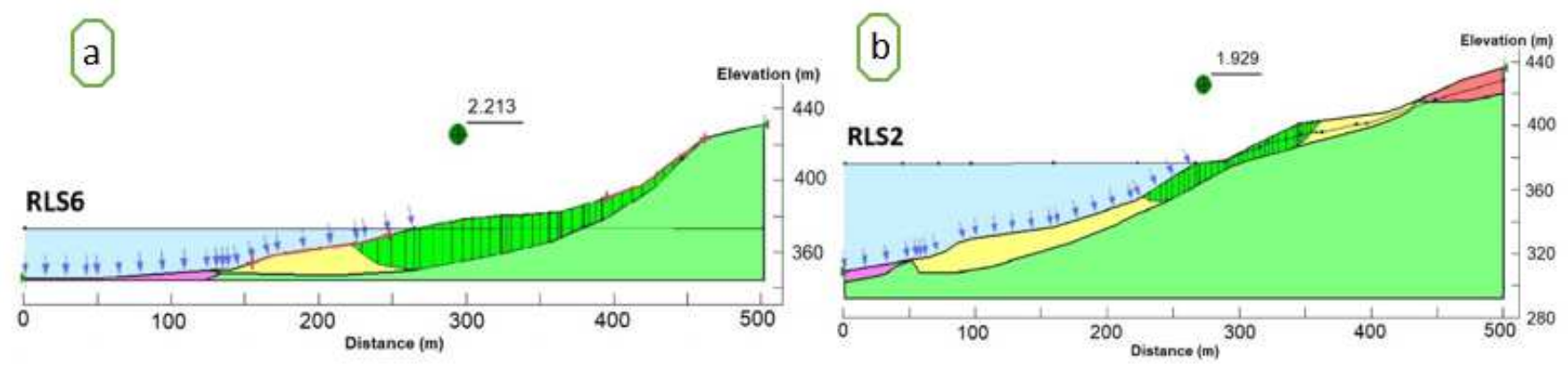

Figure 9

Stable design analysis under static conditions - full tank, a) Landslide RLS6, b) landslides RLS2 